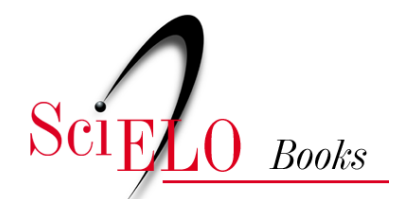

\title{
6. O problema dos colegas de quarto
}

\author{
Aline Guarnieri Gubitoso \\ Vinicius Cifú Lopes
}

\section{SciELO Books / SciELO Livros / SciELO Libros}

GUBITOSO, G., and LOPES, V. C. O problema dos colegas de quarto. In: Alocações, estabilidade e otimização: uma introdução passo a passo [online]. São Bernardo do Campo, SP: Editora UFABC, 2017, pp. 107-121. ISBN: 978-85-6857-682-3. https://doi.org/10.7476/9788568576823.0007.

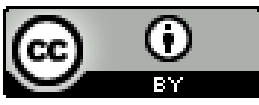

All the contents of this work, except where otherwise noted, is licensed under a Creative Commons Attribution 4.0 International license.

Todo o conteúdo deste trabalho, exceto quando houver ressalva, é publicado sob a licença Creative Commons Atribição 4.0.

Todo el contenido de esta obra, excepto donde se indique lo contrario, está bajo licencia de la licencia $\underline{\text { Creative }}$ Commons Reconocimento 4.0. 


\section{O problema dos colegas de quarto}

Nossas discussões sobre o problema do emparelhamento começaram por sua forma mais simplificada, o problema do casamento, em que se combinava cada homem a uma mulher (ou vice-versa), segundo as preferências de cada um. Depois, contemplamos sua forma generalizada no problema das admissões em universidades, porque, ao invés de combinar dois elementos (homens e mulheres), esta extensão permitia a combinação de um elemento de um grupo com vários de outro grupo, uma vez que cada universidade busca admitir uma quota de estudantes.

Nosso próximo passo é analisar o problema dos colegas de quarto, mais complexo devido ao fato de que não são grupos distintos que se combinam, mas cada pessoa ordena todas as outras segundo uma ordem de preferência, de forma que qualquer uma pode vir a ser colega de quarto.

$\rightarrow$ Definição: Semelhantemente ao problema do casamento, diz-se que um emparelhamento é instável se houver duas pessoas que não estão pareadas entre si, mas que se preferem ao invés de seus atuais pares, de modo a formarem um par de bloqueio. Caso contrário, o emparelhamento é estável. 


\section{Exercício}

1) No problema de colegas de quarto, nem toda situação admite uma solução estável; mostre que é o caso das pessoas rotuladas como घ, 1 , $2, \ldots, M$, sendo $M$ ímpar, com listas de preferência satisfazendo estas condições: — tem uma lista qualquer; todos os demais listam a em último lugar; cada $n$ entre 1 e $M-1$ prefere $n+1$ em primeiro lugar; $M$ prefere 1 em primeiro. (Note o caráter cíclico das primeiras preferências.)

Resposta: Qualquer $n$ que seja alocado a $\mathbf{m}$ prefere estar com qualquer outra pessoa, enquanto alguma delas também prefere $n$ a seu parceiro atual, seja $n-1$ (no caso $n>1$ ) ou $M$ (no caso $n=1$ ), formando um par de bloqueio.

Para descrever o procedimento de alocação nos quartos, trabalharemos com um número par de indivíduos, de modo que possam ser combinados dois a dois. Comentaremos depois a respeito do caso ímpar, em que um agente será deixado sozinho, e das extensões do problema. Toda a apresentação baseia-se em Gusfield; Irving (1989).

\subsection{Algoritmo para resolução}

O início do processo é semelhante ao do problema de casamento, com cada pessoa fazendo proposta à sua primeira opção de pessoa como colega de quarto. Entretanto, diferentemente da situação do casamento, nesta situação, todas as pessoas fazem e recebem propostas. Por conseguinte, torna-se necessário que algumas entradas sejam removidas, como descreveremos a seguir. Então, novas listas de preferência, chamadas de tabelas de preferência (atualizadas a cada nova etapa do processo), são formadas sem tais entradas. Dessa forma, as exclusões das entradas servem para excluir possíveis pares de bloqueio das tabelas de preferência.

É importante ressaltar que, quando se exclui o par $(X, Y)$, isto é, remove-se $Y$ da lista de preferências de $X$, também é preciso 
excluir o par $(Y, X)$, de forma que $X$ também seja removido da lista de $Y$. Portanto, não pode haver uma pessoa que, ao mesmo tempo em que esteja na lista de preferências de alguém, não o tenha em sua própria lista, isto é, cada membro de um possível par estável tem de permanecer na lista do outro membro.

$\rightarrow$ Notação e alerta: Para denotar a remoção de uma pessoa na lista de preferências de outra, utilizamos o símbolo ${ }^{\wedge}$, da seguinte forma: se $D$ é removido da lista de preferência de $A$, então:

$$
A: \quad B>C>E>F>\hat{D}
$$

Aqui, isso requer que A também seja removido da lista de preferência de D:

$$
D: E>\hat{A}>B>C>F
$$

O processo chega ao fim quando se alcança uma das seguintes condições: (a) alguma lista de preferência se torna vazia, caso em que não há solução estável ou (b) cada lista é reduzida a uma única entrada, de modo que a associação correspondente é estável. Portanto, devido à condição (a), uma alocação de colegas de quarto a partir de um único grupo nem sempre admite solução estável.

A fim de exemplificar o passo a passo desse algoritmo, resolveremos detalhadamente o exemplo enunciado com apenas alguns passos por Gusfield; Irving (1989, p. 171).

Tal como nos problemas anteriores, o primeiro passo é que os agentes ordenem os demais participantes segundo uma ordem de preferências, porém, com a ressalva de que, nesta situação, cada agente tem de ordenar todos os outros. Assim, temos a seguinte tabela: 


$$
\begin{array}{ll}
1: & 8>2>9>3>6>4>5>7>10 \\
2: & 4>3>8>9>5>1>10>6>7 \\
3: & 5>6>8>2>1>7>10>4>9 \\
4: & 10>7>9>3>1>6>2>5>8 \\
5: & 7>4>10>8>2>6>3>1>9 \\
6: & 2>8>7>3>4>10>1>5>9 \\
7: & 2>1>8>3>5>10>4>6>9 \\
8: & 10>4>2>5>6>7>1>3>9 \\
9: & 6>7>2>5>10>3>4>8>1 \\
10: & 3>1>6>5>2>9>8>4>7
\end{array}
$$

Como todos os agentes começam o algoritmo livres, cada um deles pode e faz uma proposta à primeira pessoa de sua lista. Consequentemente, a pessoa que fez a proposta deixa de ser livre e se torna semicombinada àquela que recebeu sua proposta, que, por sua vez, ou está livre ou está semicombinada com outra pessoa, a primeira em sua própria lista de preferências. Portanto, a relação de "semicombinação" não é simétrica.

$\rightarrow$ Notação e alerta: Para denotar a semicombinação de $A$ com $B$, utilizamos novamente a moldura $\square$ da seguinte forma em sua lista de preferência:

$$
A: B>C>E>F>D
$$

Isso significa que, como $B$ é a primeira opção disponível de $A$, este propõe a ele, de forma que $A$ está semicombinado a $B$. Porém, aqui não é necessário que $B$ esteja semicombinado a $A$, ou seja, que A esteja emoldurado na lista de preferência de $B$.

Após a formação de um par semicombinado, são removidas as entradas imediatamente após o proponente na lista de preferência do receptor, ao serem agentes menos preferíveis.

Exemplo: Se a primeira opção de $A$ é $B$, então, da lista de preferência de $B$, todas as pessoas após $A$ devem ser removidas: 


$$
\begin{array}{ll}
A: & B>C>E>F>D \\
B: & E>F>A>\hat{C}>\hat{D}
\end{array}
$$

Consequentemente, $B$ deve ser removido das listas dessas pessoas:

$$
\begin{array}{ll}
C: & E>D>F>\hat{B}>A \\
D: & E>A>\hat{B}>C>F
\end{array}
$$

De fato, ao removermos as pessoas menos preferíveis e seus pares correspondentes, $B$ tem $A$ como última opção, já que as opções posteriores foram superadas pela proposta de $A$. Logo, os pares $(B, C)$ e $(B, D)$ já não mais devem aparecer nas listas de $B, C$ e $D$, devido à preferência de $B$ por $A$.

Entretanto, ao considerarmos que cada pessoa de um possível par estável somente pode permanecer na lista de outra pessoa se ela mantém essa pessoa em sua própria lista, as remoções dos pares têm de ocorrer imediatamente após a formação da semicombinação. Em vista disso, se a primeira ou uma próxima opção de uma pessoa for removida, quando ela for fazer a proposta, essa opção removida já não mais aparece em sua lista (assim como ela não aparece na lista dessa opção), de forma que sua proposta é diretamente feita à opção seguinte.

Dessa forma, para que cada nova tabela de preferências formada seja estável, três condições devem ser respeitadas: (a) o agente, que é a primeira opção de par de uma pessoa, deve tê-la como última opção de par; (b) se o par $(X, Y)$ não ocorre nas listas de $X$ ou $Y$, então $X$ prefere sua última opção a $Y$ ou $Y$ prefere sua última opção a $X$ (de forma que este par já tenha sido removido) e (c) ninguém deve ter sua lista de preferência vazia.

Apliquemos isso às listas dadas:

\section{$1^{\text {a }}$ Rodada - propostas e remoções}

Quando 1 propõe a 8, ele fica semicombinado a 8, então removem-se os agentes que aparecem depois de 1 na lista de preferências 
de 8 , a saber, 3 e 9 . Não devemos nos esquecer que, como 3 e 9 foram removidos da lista de 8 , então 8 também deve ser removido das listas de 3 e 9. Logo, 1, ao ser semicombinado com 8, faz com que os pares $(8,3),(3,8),(9,8)$ e $(8,9)$ sejam removidos. Ou seja:

$$
\begin{aligned}
& 1: \quad 8>2>9>3>6>4>5>7>10 \\
& 3: \quad 5>6>\hat{8}>2>1>7>10>4>9 \\
& 8: \quad 10>4>2>5>6>7>1>\hat{3}>\hat{9} \\
& 9: \quad 6>7>2>5>10>3>4>\hat{8}>1
\end{aligned}
$$

Analogamente, 2 é semicombinado com 4 (removem-se 5 e 8 da lista de 4 e 4 das listas de 5 e 8); 3 é semicombinado com 5 (removem-se pares de 5 com 1 e 9); 4 é semicombinado com 10 (removem-se pares de $10 \mathrm{com}$ 7); 5 é semicombinado com 7 (removem-se pares de 7 com 10, 4, 6 e 9); 6 é semicombinado com 2 (removem-se pares de 2 com 7 ).

Com 7 , a proposta parece um pouco diferente, pois, como se removeu sua primeira opção de sua lista de preferências, 2 , a nova primeira opção de 7 é 1 (considere que as remoções ocorrem imediatamente após a formação das semicombinações), de modo que 7 faz uma proposta a 1 e, assim, é semicombinado a ele (removem-se pares de 7 com 10).

Ao continuarmos o processo de proposta, 8 faz uma proposta a 10 , que já estava semicombinado com 4 , de forma que 10 tem de escolher entre 4 e 8; como 8 é mais preferível que 4 em sua lista, 10 prefere 8. Assim, 8 é semicombinado com 10 (removem-se pares de 10 com 4 e 7, entretanto, com 7 não é necessário, pois já foi removido em momento anterior). Consequentemente, a semicombinação de 4 com 10 é quebrada e 4 torna-se livre.

Finalmente, 9 é semicombinado com 6 (não se remove pares) e 10 é semicombinado com 3 (removem-se pares de 3 com 4 e 10).

Em síntese, houve as seguintes propostas: 


$$
\begin{array}{c|c|c}
1 m 8 & 4 m 10 & 8 m 10 \\
2 m 4 & 5 m 7 & 9 m 6 \\
3 m 5 & 6 m 2 & 10 m 3 \\
& 7 m 1 &
\end{array}
$$

Com a formação de todas as semicombinações e seus pares a serem removidos, a nova tabela de preferências é:

$$
\begin{aligned}
& 1: \quad 8>2>9>3>6>4>\hat{5}>7>\hat{10} \\
& 2: \quad 4>3>8>9>5>1>10>6>\hat{7} \\
& 3: \quad 5>6>\hat{8}>2>1>7>10>\hat{4}>\hat{9} \\
& 4: \quad \hat{10}>\hat{7}>9>\hat{3}>1>6>2>\hat{5}>\hat{8} \\
& 5: \quad 7>\hat{4}>10>8>2>6>3>\hat{1}>\hat{9} \\
& 6: \quad 2>8>\hat{7}>3>4>10>1>5>9 \\
& 7: \quad \hat{2}>1>8>3>5>\hat{1}>>\hat{4}>\hat{6}>\hat{9} \\
& 8: \quad 10>\hat{4}>2>5>6>7>1>\hat{3}>\hat{9} \\
& 9: \quad 6>\hat{7}>2>\hat{5}>10>\hat{3}>4>\hat{8}>1 \\
& 10: \quad 3>\hat{1}>6>5>2>9>8>\hat{4}>\hat{7}
\end{aligned}
$$

\section{$2^{\mathrm{a}}$ rodada - propostas e remoções}

Os agentes que ficaram livres fazem uma nova proposta à melhor opção em sua lista que ainda não foi removida, enquanto os demais mantêm suas propostas.

Como somente 4 ficou livre, porque sua primeira opção recebeu uma proposta melhor, apenas ele fará uma nova proposta. Sua próxima opção é 9 (em vista das exclusões anteriores). Dessa forma, 4 faz uma proposta a 9 e é semicombinado a ele. Removem-se, então, os pares $(9,1)$ e $(1,9)$.

$$
\begin{array}{l|c|c}
1 \rightsquigarrow 8 & 4 m 9 & 8 m 10 \\
2 m 4 & 5 m 7 & 9 m 6 \\
3 m 5 & 6 \rightsquigarrow 2 & 10 \rightsquigarrow 3 \\
& 7 m 1 &
\end{array}
$$


Com a modificação da semicombinação de 4 e as remoções da rodada anterior já apagadas, a nova tabela de preferências é:

$$
\begin{array}{ll}
1: & 8>2>\hat{9}>3>6>4>7 \\
2: & 4>3>8>9>5>1>10>6 \\
3: & 5>6>2>1>7>10 \\
4: & 9>1>6>2 \\
5: & 7>10>8>2>6>3 \\
6: & 2>8>3>4>10>1>5>9 \\
7: & 1>8>3>5 \\
8: & 10>2>5>6>7>1 \\
9: & 6>2>10>4>1 \\
10: & 3>6>5>2>9>8
\end{array}
$$

(Note a exclusão de 9, 1 nas listas de 1, 9, respectivamente.)

Esse processo continua enquanto houver alguma pessoa livre, cuja lista de preferências não esteja vazia, isto é, até que todas as pessoas façam suas propostas e fiquem semicombinadas a alguém, como ocorre nesta rodada em nosso exemplo.

Se houver alguma lista de preferências vazia depois das exclusões de pares, o problema não tem solução estável (lembrando que, aqui, se trata de um número par de pessoas).

Se ocorrer a existência de uma única entrada em cada lista de preferência, há uma única alocação estável possível entre os colegas de quarto, indicada pelas próprias listas. Isso porque, quando uma pessoa $A$ foi removida da lista de outra $B$, também $B$ foi removido da lista de $A$, então a única pessoa $C$ na lista de $A$ não pode ter removido $A$; pelo contrário, tem $A$ como única entrada em sua lista, formando o par $A-C$. A estabilidade é garantida pelo mesmo raciocínio de Gale-Shapley, porque cada pessoa propôs sucessivamente a seu melhor candidato e só foi rejeitada quando este recebeu proposta melhor.

Contudo, se nenhuma dessas duas situações ocorrerem, então, o algoritmo passa para a sua próxima fase, de que falaremos a seguir. 
No seu término, novamente, as duas situações acima também são possíveis, com as mesmas conclusões, mas, agora, as listas de preferências são reduzidas ao excluírem-se rotações. Logo, a solução encontrada depende da ordem com que se eliminam as rotações.

$\rightarrow$ Definição: Rotações são ciclos que identificam as preferências comuns entre grupos de pessoas. Por exemplo, tome as listas de preferências de $C$ e $F$ :

$$
\begin{aligned}
& C: E>D>\ldots \\
& F: D>E>\ldots
\end{aligned}
$$

Podemos perceber que $E$ é a primeira opção de $C$ e a segunda opção de $F$, assim como $D$ é a segunda opção de $C$ e a primeira opção de $F$, formando este diagrama:

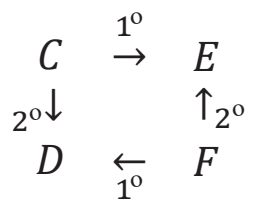

Girar o diagrama $180^{\circ}$ permuta $C$ com $F$ e $D$ com $E$, mas preserva a orientação e o rótulo de cada flecha, daí o nome "rotação".

Ressaltamos que esses ciclos podem ser maiores ao abranger mais do que somente duas pessoas com preferências comuns, como veremos na segunda remoção.

$\rightarrow$ Propriedade: No exemplo da definição, como $C$ está semicombinado a $E$, então $C$ é a última entrada na lista de preferência de $E$, após as remoções dos passos anteriores. Como $E$ consta na lista de $F$, também $F$ consta na lista de $E$, então concluímos que $F>{ }_{E} C$. Caso $D$ rejeite $F$, o par $(F, E)$ passa a bloquear o par $(C, E)$. Devemos, portanto, remover o par $(C, E)$ e, por simetria, o par $(F, D)$. 
Ao observarmos a última tabela obtida, percebemos uma rotação entre as preferências de 1 e de 6 , isto é, a primeira opção de um coincide com a segunda opção do outro e vice-versa. Assim, deve ser removida a primeira opção de cada pessoa, isto é, os pares $(1,8)$ e $(6,2)$, além dos seus correspondentes $(8,1)$ e $(2,6)$. Em consequência dessas exclusões, a primeira opção de 1 passa a ser 2 e, ao ser semicombinada a ela, devem ser removidos da lista de 2 os agentes menos preferíveis que 1 , correspondendo aos pares $(2,10)$ e $(10,2)$ porque $(2,6)$ e $(6,2)$ já foram excluídos. Agora, porque 6 é semicombinado a 8 , excluem-se também os pares $(8,7)$ e $(7,8)$. Efetuamos tais alterações na tabela:

$$
\begin{array}{ll}
1: & \hat{8}>2>3>6>4>7 \\
2: & 4>3>8>9>5>1>\hat{10}>\hat{6} \\
3: & 5>6>2>1>7>10 \\
4: & 9>1>6>2 \\
5: & 7>10>8>2>6>3 \\
6: & \hat{2}>8>3>4>10>1>5>9 \\
7: & 1>\hat{8}>3>5 \\
8: & 10>2>5>6>\hat{7}>\hat{1} \\
9: & 6>2>10>4 \\
10: & 3>6>5>\hat{2}>9>8
\end{array}
$$

Dessa forma, uma nova tabela de preferências é formada, na qual a próxima rotação observada ocorre entre 3 agentes, sendo eles 1,9 e 10 :

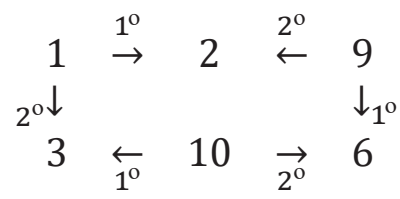

Excluímos, então, a primeira opção de cada agente, sendo os pares $(1,2),(9,6)$ e $(10,3)$, não esquecendo seus correspondentes 
$(2,1),(6,9)$ e $(3,10)$. Logo, 1 é agora semicombinado a 3 e precisam ser removidos os pares $(3,7)$ e $(7,3)$, porque os pares $(3,10)$ e $(10,3)$ já foram removidos, ao passo que, como 9 passa a ser semicombinado a 2 , também são removidos os pares $(2,5)$ e $(5,2)$, porque os pares $(2,1)$ e $(1,2)$ já foram removidos. Já 10 , por parear-se a 6 , remove os pares $(6,1),(1,6)(6,5)$ e $(5,6)$, porque os pares $(6,9)$ e $(9,6)$ já foram removidos. Obtemos:

$$
\begin{array}{ll}
1: & \hat{2}>3>\hat{6}>4>7 \\
2: & 4>3>8>9>\hat{5}>\hat{1} \\
3: & 5>6>2>1>\hat{7}>\hat{10} \\
4: & 9>1>6>2 \\
5: & 7>10>8>\hat{2}>\hat{6}>3 \\
6: & 8>3>4>10>\hat{1}>\hat{5}>\hat{9} \\
7: & 1>\hat{3}>5 \\
8: & 10>2>5>6 \\
9: & \hat{6}>2>10>4 \\
10: & \hat{3}>6>5>9>8
\end{array}
$$

Nessa nova tabela de preferência, encontramos outra rotação, agora entre 1 e 2 , de modo que os pares removidos são $(3,1),(1,3)$, $(2,4),(4,2)$, também $(4,6)$ e $(6,4)$ pela nova semicombinação 1 m 4 .

$$
\begin{array}{ll}
1: & \hat{3}>4>7 \\
2: & \hat{4}>3>8>9 \\
3: & 5>6>2>\hat{1} \\
4: & 9>1>6>\hat{2} \\
5: & 7>10>8>3 \\
6: & 8>3>4>10 \\
7: & 1>5 \\
8: & 10>2>5>6 \\
9: & 2>10>4 \\
10: & 6>5>9>8
\end{array}
$$


A rotação subsequente envolve 3 e 10. Assim, são removidos $(3,5),(5,3),(10,6),(6,10)$, mais $(5,8)$ e $(8,5)$ pela nova semicombinação 10 m 5 .

$$
\begin{array}{ll}
1: & 4>7 \\
2: & 3>8>9 \\
3: & \hat{5}>6>2 \\
4: & 9>1 \\
5: & 7>10>\hat{8}>\hat{3} \\
6: & 8>3>10 \\
7: & 1>5 \\
8: & 10>2>\hat{5}>6 \\
9: & 2>10>4 \\
10: & \hat{6}>5>9>8
\end{array}
$$

Acima, ocorre uma rotação entre 8 e 9 . Consequentemente, os pares $(8,10),(10,8)$. $(9,2)$ e $(2,9)$ são removidos.
1: $4>7$
6: $8>3$
2: $3>8>\hat{9}$
7: $1>5$
3: $6>2$
8: $\hat{10}>2>6$
4: $9>1$
9: $\hat{2}>10>4$
5: $7>10$
10: $5>9>\hat{8}$

Na nova tabela formada, ainda ocorre rotação, entre 2 e 6 , de forma que os pares $(2,3),(3,2),(6,8)$ e $(8,6)$ são removidos.
1: $4>7$
6: $\hat{8}>3$
2: $\hat{3}>8$
7: $1>5$
3: $6>\hat{2}$
8: $2>\hat{6}$
4: $9>1$
9: $10>4$
5: $7>10$
10: $5>9$

Por fim, percebemos uma última rotação entre 4, 7 e 10; removem-se, então, os pares $(4,9),(9,4),(7,1),(1,7),(10,5)$ e $(5,10)$. 

1: $4>\hat{7}$
2: 8
6: 3
7: $\hat{1}>5$
3: 6
4: $\hat{9}>1$
8: 2
5: $7>\hat{10}$
9: $10>\hat{4}$
10: $\hat{5}>9$

Após as eliminações, resta apenas um agente em cada lista de preferência e, pelo mesmo motivo que argumentamos ao final da primeira etapa, os agentes remanescentes combinam-se aos pares de modo estável:

\begin{tabular}{ll|l|l|} 
1: & 4 & 6: & 3 \\
2: & 8 & $7:$ & 5 \\
3: & 6 & 8: & 2 \\
4: & 1 & $9:$ & 10 \\
5: & 7 & 10: & 9
\end{tabular}

Portanto, obtivemos um emparelhamento estável com os pares: $1-4,2-8,3-6,5-7$ e $9-10$.

\section{Variantes}

Prometemos relatar como uma solução para o problema dos colegas de quarto deve ser procurada em três casos: um número ímpar de agentes; listas de preferência incompletas em vista de opções inaceitáveis; listas de preferência com indiferença. Gusfield; Irving (1989) explicam as adaptações necessárias em suas três Seções 4.5.1, 4.5.2, e 4.5.3, respectivamente, que resumimos aqui.

No caso de um número ímpar de pessoas a combinar duas a duas, em qualquer emparelhamento alguma deverá sobrar sem colega de quarto. Convenciona-se que essa pessoa solitária ocasiona um bloqueio se for a preferida de uma outra com relação ao colega de quarto desta. Mostra-se que, então, em todos os emparelhamentos estáveis (se houver) para um mesmo cenário de listas de 
preferência, a mesma pessoa permanece solitária e ela é identificada como a única cuja lista aparece vazia ao final da primeira etapa do algoritmo. Após sua remoção, a segunda etapa pode ser aplicada ao número par de agentes restantes (que determinará se uma solução estável existe ou não).

No caso de listas incompletas, quando há soluções estáveis, mostra-se que cada pessoa participante ou sempre consegue algum colega em todos os emparelhamentos estáveis, ou sempre resta solitária, sendo que as pessoas solitárias são identificadas com suas listas de preferência esvaziadas após a primeira etapa do algoritmo. Também após a remoção destas pessoas, a segunda etapa determina a existência ou não de uma solução estável.

Finalmente, no caso de indiferenças, podemos substituir o símbolo “”” pelo símbolo “>” em cada lista e, então, proceder com o algoritmo. Contudo, como o problema dos colegas de quarto nem sempre tem solução, é concebível que uma escolha aleatória da nova ordem estrita entre agentes equivalentes não produza um emparelhamento estável, enquanto outra sim. Pode-se identificar todas essas possíveis escolhas e combiná-las, para testar cada conjunto de listas de preferência estrita até encontrar um que admita solução estável. Tal processo, entretanto, é muito ineficiente, porque a quantidade de combinações a tratar pode crescer exponencialmente em função do número de agentes envolvidos. Certamente pode haver uma saída mais inteligente, mas mostra-se que o próprio problema, em um sentido formal, é computacionalmente complexo.

\subsection{Relação com o problema do casamento}

Suponha que começamos com um problema de casamento entre grupos de mesmo número de homens e mulheres, com listas completas. Ao final de cada lista de preferência de um homem (ou mulher), acrescente os demais homens (ou mulheres, respectivamente) em uma ordem arbitrária, obtendo listas de preferência para um problema de colegas de quarto. 
Por um lado, qualquer emparelhamento estável entre os grupos de homens e mulheres, como solução ao problema do casamento, também é estável como solução para esse problema de colegas de quarto: não há pares de bloqueio formados por um homem e uma mulher (já que, se existissem, bloqueariam os casamentos originais), nem pares formados por dois homens ou duas mulheres, porque cada membro foi colocado, na lista do outro, após seu parceiro.

Por outro, não pode haver qualquer novo emparelhamento estável: se houver dois homens em um quarto e duas mulheres em outro, bastará formar um par qualquer com um desses homens e uma dessas mulheres para bloquear o emparelhamento, já que se preferirão entre si em relação aos colegas de quarto que vêm no final de suas listas.

Assim, como sempre há uma alocação estável entre homens e mulheres, se realizarmos o procedimento acima, então obteremos um emparelhamento dentro da união dos conjuntos de homens e mulheres, que de fato combina homens a mulheres e é uma solução estável para o problema de casamento. Exceto por saber-se de antemão que o problema do casamento pode ser sempre resolvido, esta é uma pequena redução ao problema de colegas de quarto. (GUSFIELD; IRVING, 1989, lema 4.1.1.)

Enquanto a primeira parte do algoritmo dos colegas de quarto, referente às propostas dos indivíduos, é semelhante ao mecanismo deferred acceptance de resolução do problema do casamento, a segunda parte é nova, ao utilizar um outro procedimento intitulado minimal differences ("diferenças mínimas").

É esse o algoritmo responsável pela eliminação das rotações, que reduz as listas de preferência até que ou alguma lista se torne vazia, caso em que não há solução estável, ou cada lista seja reduzida a uma única entrada, de modo que a associação correspondente é estável. Contudo, como há várias ordens em que as rotações podem ser identificadas e escolhidas para serem eliminadas, o emparelhamento obtido não precisa ser único (em contraste com Gale-Shapley no problema do casamento). Por outro lado, as rotações ocorrem também no problema do casamento e são instrumentais em investigações mais avançadas. 